\title{
Fathers and work-life balance in France and the UK: policy and practice
}

\begin{abstract}
Purpose - This paper focuses on the role of organizations in mediating the impact of national work-life balance (WLB) policy on employees, in particular fathers.

Design/methodology/approach - It presents existing research about WLB policy implementation in organizations as well as the findings of empirical work in insurance and social work in France and the UK (questionnaire survey, case study analysis, interviews with national and sector-level trade union officials).

Findings \& Practical implications - These indicate that fathers' take-up of WLB policies is the outcome of a complex dynamic between national fatherhood regimes, organizational and sector characteristics and the individual employee. They suggest that fathers tend to use WLB measures to spend time with their families where measures increase their sense of entitlement (state policies of paternity leave) or where measures offer non-gendered flexibility (reduced working time/organizational systems of flexitime). In line with other studies it also finds that fathers extensively use informal flexibility where this is available (individual agency). These findings have implications for way WLB policies are framed at national and organizational level.

Originality/value - Cross-national comparative research into WLB policy and practice at national and organizational level is very rare. The empirical work presented in this article, although exploratory, makes a significant contribution to our understanding of WLB policy and practice, particularly as it relates to fathers.

Key words - Britain, fathers, fatherhood regime, France, insurance, organizations, social work, WLB.
\end{abstract}

\section{INTRODUCTION}

Fathers' roles within the home and the workplace have come under increasing academic and public policy scrutiny in recent years, for two main reasons. First, governments have sought to remove obstacles to female labour market participation by looking in particular at reasons for and possible solutions to mothers' withdrawal from the labour market: hence the growing interest in the work-life balance (WLB) agenda (OECD, 2004) ${ }^{\mathrm{i}}$. They have also become drawn into the private sphere as they seek to encourage a more balanced distribution of domestic tasks in order to relieve women of their double burden.

Second, in the UK at least, there has been a (largely child-centred) social policy concern with strengthening families and in particular paternal involvement, in order to enhance social cohesion. As a result, "fatherhood regimes" - incorporating fatherhood rights and fatherhood obligations to include breadwinner models and cultural norms with respect to parenting roles, along with the impact of working time regimes (Authors, 2008; Hobson and Martin, 2002) - are being reframed to emphasize fathers' rights and responsibilities within couple households and post-separation (Gambles et al, 2007).

Nevertheless, WLB tends to be framed in a gendered way, in terms of mothers' ability to juggle work and family. Why this should be the case is a matter of continued academic debate, focusing in particular on gender attitudes within society and at a micro level as 
they are negotiated within households, that is, on the relationship between structural and interactional change (Martin, 2003; Risman, 2004). The process of reciprocal change between men and women is multi-level (Deutsch, 2007; Gambles et al, 2007: 17). Work organizations play a crucial mediating role within this complex and dynamic set of relationships (Brandth and Kvande, 2001; das Dores Guerreiro and Pereira, 2007; Gambles et al, 2007; Haas and Hwang, 2007). They provide their own framework for individuals to negotiate their own balance between work and family, or in which individuals are constrained in their choices. Fathers' roles are therefore both dynamic and embedded within organizational policies and practices, themselves shaped by the economic and institutional environment in which they operate.

In this paper we seek to explore the interaction between national policy frameworks and the implementation of WLB initiatives in French and British organizations, with particular reference to fathers. We draw on fieldwork carried out in France and the UK in 2001-2005, in insurance and social work (see Authors, 2006). In this research we sought to discover how WLB initiatives were framed, negotiated and implemented. We also sought to uncover more about the relationship between individual and organizational practice, particularly as it relates to fathers.

France and the UK provide useful cases for comparative research because they represent different working time regimes, gender regimes, and welfare state regimes (see e.g. Gornick and Meyers, 2004). Against this backdrop countries have recently seen broadly convergent changes in their fatherhood regimes but, as we argue elsewhere, these changes are incomplete and ambiguous (Authors, 2008) and are likely to have a limited impact on organizational and individual practices. Nevertheless, they do provide at least a window of opportunity in which individual practices can potentially be negotiated.

Our research examines the relationship between national policy and organizational practice. The Nordic model indicates that strong institutional (e.g. ensuring a high level of wage compensation for parental leaves) and cultural support for egalitarian gender roles has an impact on organizational policy and on men's take-up of organizational measures (Björnberg, 2000). Elsewhere, cross-national comparative European research suggests that in some cases organizational provision may compensate for state passivity (Holter, 2007); in other cases, a strong role for the state may lead organizations to absolve themselves of responsibility for WLB (see e.g. Båck-Wikland and Plantin, 2007; Haas et al, 2000). The comparative framework of our project allows us to examine the institutional and cultural environment and its impact on the workplace.

In the following sections we first review existing research about fathers' WLB and organizational practice, then go on to present the broader institutional and policy context for both countries before discussing our findings in the context of existing research. We focus in particular on the impact of legislative frameworks and sectoral features of WLB in our case study organizations; and, within these organizations, our findings highlight the importance of the management/non-management divide and line managers on the practice of WLB. 


\section{FATHERS, ORGANIZATIONS AND WLB}

Our project drew on existing research about the gendered impact of WLB in work organizations, largely in the USA, Australia and the UK. Since carrying out our research we have also been able to compare our findings with those of other cross-national projects conducted around the same time (Halrynjo, 2009; Holter, 2007; Langvasbräten and Teigen, 2006).

Comparative European research suggests that processes of change start at home and are brought into jobs, rather than the other way round (Holter, 2007; Singley and Hyman, 2005). Fathers negotiate their domestic role with partners, in particular when their partner works; men's breadwinner role is shaped by partners' expectations as well as their own gender role attitudes and aspirations. Work organizations then present opportunities and constraints for the realization of men's aspirations for WLB (and couples' negotiations of the trade-off between paid work and domestic responsibilities) (Brandth and Kvande, 2001). This process is of course two-way: the workplace is a significant determinant of paternal involvement with their children, alongside other institutional practices such as welfare policies and provision, personal biography and family dynamics, income, education and social class (eg. Lamb et al, 1997; Warren, 2003). But given the central importance of paid work for men's identity (Dermott, 2006; Hatten et al, 2002), fathers' expectations and norms are also strongly influenced by the workplace environment.

Research on take-up of WLB measures in organizations has identified key factors in the organizational work-life culture such as the degree of feminization of the workforce, the extent of manager and co-worker support, the career consequences of taking a WLB measure, organizational time expectations, and gendered perceptions of policy use (McDonald et al, 2005; Haas and Hwang, 2007). The importance of these factors is confirmed by research about "father-friendly" organizations which emphasizes in addition the role of managers as champions or leaders, the strong gendering of care roles and their association with motherhood and the heavy constraints of presenteeism and long hours cultures (Langvasbräten and Teigen, 2006; see also Bond et al, 2002; Gambles et al, 2006; Smithson and Stokoe, 2005). Gendered perceptions of care within organizations (Bittman et al, 2004; Holter, 2007) reduce men’s sense of entitlement to workplace WLB measures (Lewis and Smithson, 2001) and "organizational career cultures" prevent men from overtly choosing WLB over their career.

Part-time work and reduced hours, for example, are often seen as corresponding to a "mommy track" and for this reason are considered to penalize men more than women (Holter, 2007). Hence, women with dependent children are most likely to take-up measures such as part-time working and reduced hours, and term-time working (where it is available, mostly in the public sector) is almost exclusively female. Men, by contrast, are often found using informal flexibility, or taking advantage of gender-neutral flexibility such as flexi-time systems, to improve their WLB at the margins (Burgess, 1997; Singley and Hynes, 2005; Authors, 2006). This difference is seen as a prime 
example of a "logic of gendered choices" (Risman, 1998: 29) whereby couples' use of policies appear "to flow from interactional processes that defined women's jobs and careers as more flexible and their role in family life as more primary" (Singley and Hynes, 2005: 391). Organizational policies and practices have been found to influence and reinforce these interactional perceptions and choices, thus creating or encouraging a polarization between men and women's working experiences.

On the other hand, it has been suggested that by responding to men's gendered use of working time, organizational policies can help men to negotiate more family time and therefore legitimate an alternative to presenteeism (Langvasbräten and Teigen, 2006). Thus, informal support and flexibility in fathers' working hours were most frequently found in the most "father-friendly" organizations in Haas and Hwang's (2007) study of Swedish organizations.

In addition, research shows that men are more likely to take up measures where their sense of entitlement is clearly backed up by legal provision, such as state-backed paternity leave (Brandth and Kvande, 2001; Holter, 2007). These findings indicate that family-friendly policies such as parental leave and flexible working hours can indeed help to overcome such constraints and facilitate men's involvement with their children (eg. Fagnani and Letablier, 2004; Hatten et al, 2002; Pleck, 2003), if WLB is framed in a way that addresses men's as well as women's specific work-life constraints (Brannen and Moss, 1998). However, few companies aim WLB policies at men in this way (Haas and Hwang, 2007; Wise and Bond, 2003).

However, changing organizational structures, flexible work organization (lean production and supply chain management in manufacturing and retailing, and new service requirements in both public and private sector services) and work intensification throw up new challenges to WLB (Perrons et al, 2007). Although "high-performance" management is found to be associated with the formal presence of WLB policies, in the UK at least (Dex and Smith, 2002), there has been concern about the negative impact of such practices on the WLB of individuals, particularly men (Brandth and Kvande, 2001; Kvande, 2009; White et al, 2003), and it has been argued that a discourse of employeefriendly work practices disguises employer-friendly practices which only indirectly enhance individual WLB, if at all (Fleetwood, 2007: 394). In interviews, men are strongly critical of this gap between organizational discourse and reality (Holter, 2007).

This review of existing research indicates two key questions for our discussion here:

1. how do national institutional frameworks for WLB impact on work organizations and fathers' take-up of such measures?

2. what organizational (and sectoral) constraints shape WLB policy provision and delivery, particularly as they relate to fathers?

Before attempting to respond to these questions through our empirical findings, we now briefly present the fatherhood regimes in the UK and France. 


\section{FATHERHOOD REGIMES IN THE UK AND FRANCE}

Cross-national comparative work finds significant similarities in fathers' rights and obligations in Britain and France, notably an increased recognition, inspired in part by EU policy, of the benefit of fathers' involvement with their children and the introduction of measures devised to encourage a better WLB for both men and women. Hence, in both countries civil law has developed moderate rights for fathers with the establishment of the principle of joint parenting, along with parental leave schemes, the introduction and/or extension of paternity leave as well as the development of advisory vehicles regarding fathers' role as parents. However, in practice the impact of such measures has been limited. Decisions about the care and place of residence of divorced children often continue to be made on the basis of traditional conceptions of maternal competence in the care of (particularly young) children. Also, while up-take of paternity leave has recently improved in both countries, only a tiny proportion of fathers modify or reduce their working patterns to take care of children (Pailhé and Solaz, 2006).

Despite similarities in fathers' right and obligations in Britain and France, significant differences persist in breadwinner models and cultural norms with respect to parenting roles in the two countries, reflecting in part the impact of well-documented state family and employment policies. Although levels of part-time working have increased significantly in the private sector in France since the mid-1970s (Le Feuvre and Lemarchant, 2007), the male-breadwinner/part-time carer model remains much more prevalent in Britain than in France, where, by contrast, the female carer/collective childcare model has developed. The French model is characterized by lower levels of female activity rates overall than in the UK but higher levels of full-time working, notably among mothers. Attitudinal survey evidence consistently bears out the distinctive labour market behaviour of mothers and fathers in the two countries (Künzler, 2002; Wall, 2007) finding a clear duality of attitudes in France where traditional gendered attitudes towards care roles exist, despite public support for female labour market participation, resulting in high levels of work-life stress for French working women (Crompton et al, 2005).

The working time regime is also an important structural factor in influencing individual and organizational behaviour. The British model of full-time male earner plus part-time female carer (with particularly low pay rates for female part-time employees) creates pressures on men to work longer hours than their counterparts in other European countries (Cousins and Tang, 2004). The UK’s long-work-hours regime is regularly highlighted by researchers as problematic for WLB and the gendered division of labour but has not been addressed fundamentally by the UK government, which has preferred to focus on temporal flexibility rather than working-time reduction as a solution to WLB. The resulting long-hours regime, combined with relatively few supportive policies, leads to high levels of work-life stress (Crompton et al, 2005) and restricts fathers' ability to be involved with their children, particularly when working over 50 hours a week (Day, 2006; Ferri and Smith, 1996).

In France, by contrast, working-time reduction appears to have enabled (some) fathers to spend more time with their children at weekends and during longer vacations (Fagnani 
and Letablier, 2004; Le Feuvre and Lemarchant, 2007 ; Meda and Orain, 2002). However, for many employees the working-time reduction has been exchanged for flexibility, irregular schedules and loss of control over working hours (Fagnani and Letablier, 2007) and the basic gendered division of labour had not been altered. More recently, the social benefits of working-time reduction have been eroded as the government has introduced incentives (via overtime) ${ }^{\mathrm{ii}}$ for longer hours..

Against this backdrop the WLB discourse in Britain and France, though evolving, has been rather patchy with governments calling on business to differing degrees to take forward this discourse. Britain has seen a high profile government drive to improve families' WLB through its own Work-life-Balance campaign, a key component of which has been its engagement of business as champions for change. The campaign has been enhanced by improved employee rights to request flexible or reduced working hours. A survey of British fathers suggests that the increased availability of flexible working options in companies, particularly in larger firms and those in the public sector, may be benefiting fathers (Smeaton and Marsh, 2006).

By contrast, French organizations have not significantly been drawn into debate over WLB: working time reduction has been the focus of trade-union and employer engagement focused on generating employment and increasing productivity; by contrast measures relating to the private sphere have been seen traditionally as resting with the state via the implementation of family policy. However, the French government has recently encouraged companies to bargain on WLB issues, in line with the European legislation on equality and diversity at work, leading to some companies' development of child-care facilities and flexible working (see Authors, 2008).

In sum, we see that fatherhood regimes in Britain and France have evolved in both countries but that the process of change is incomplete and far from coherent. A key difference between the two countries lies in the way fatherhood is constructed through the intersection of employment and family-based rights, in particular through workingtime regimes. Work organizations respond to legislative agendas in both countries, whether via collectively bargained implementation of laws in the French case or more pro-actively but unevenly in the British case in response to local labour markets and corporate policies. However, the role of work organizations in both countries has been perceived by academics as problematic, or at the very least ambiguous ,in terms of the duration and/or organization of working time. It is in this setting that we seek to explore via our empirical research the role of organizations in mediating the impact of national WLB policy on employees, in particular fathers, and in enabling them to achieve WLB.

\section{FATHERS AND WLB IN BRITAIN AND FRANCE: EXPLORING ORGANIZATIONAL CULTURES}

The results presented here form part of an exploratory, comparative study of fathers and WLB funded by the Caisse Nationale des Allocations in France and the British Academy, which involved research ${ }^{\text {iii }}$ in two sectors - insurance and social work - in both countries. 
These sectors were chosen for a number of reasons: firstly, so we could explore policy and practice in the private and public sectors. Research has shown that work-life balance is more likely to be found in the public sector (e.g. Silvera et al, 2004) although there is some suggestion of a gap between policy and practice (Dex and Smith, 2002). Secondly, we wished to consider the impact of occupational/sector-specific values (for example, case study research highlights sector-specific values and cultures for engineers and for "knowledge workers": see Authors, 2009); in this case, we expected social work's caring and egalitarian values which challenge masculine hegemony (Haas and Hwang, 2007) to encourage father-friendliness at work. The sectoral focus also allowed us to reflect on the potential impact of major restructuring and work reorganization on work-life balance measures: both sectors had undergone major restructuring in recent years, and at the time of the research social work was experiencing a severe recruitment and retention crisis in both countries.

Thirdly, several surveys have linked availability and take-up of work-life balance measures - including by men - to the feminization of the workforce (Cully et al, 1999) although other research disputes these findings (for a discussion, see Haas and Hwang, 2007: 60). Moreover, it has also been argued that "gynocentric" organizations overemphasize parenting as motherhood and deter fathers from taking up WLB measures. In both France and the UK approximately half of the workforce in insurance is female. Social work, by contrast, traditionally employs very high proportions of women (over $90 \%$ in both countries). We therefore expected both sectors, but particularly social work, to have developed a range of WLB policies (see also Silvera et al, 2004).

A fourth reason was that literature (Huw et al, 1999) suggested that home working was growing in financial services and was male-dominated and we sought to explore this development cross-nationally. Lastly, we hoped that an examination of these sectors would enable us to explore the role of team-working versus individual on employees' work-life balance. Recent research had suggested that work cultures based on team work were more conducive to flexible working than individual working (Hojgaard, 1998; see also Holter, 2007).

The research was carried out at macro (national level), meso (organizational level) and micro (individual) level (for a full presentation of the research methodology, see authors, 2006). Research in the two sectors was conducted through the use of questionnaire surveys, organizational case studies (interviews with human resource managers, line managers and trade union representatives) and in-depth interviews with fathers. The questionnaire research was carried out from June 2004 to December 2005. Questionnaires were sent to the Director of Human Resources or the Human Resources Department. They were completed by a range of respondents depending on the sector and the size of the organization. Response rates were relatively low (ranging from 20\% to 37\%); however in insurance the sample represented all the major types of provider and size of organization and in social work the sample represented a wide geographical spread and a good range of sizes and types of local authority. 
The questionnaire included a dozen questions about the availability of WLB measures and access to them (range of measures and policies, motivations for such measures, their implementation and monitoring) and a further seven questions about the organization and its working time practices. We distinguished between WLB measures which are broadly thought to be "family-friendly" (the ability to switch from full-time to part-time, termtime working, flexitime and job share) to other flexibility measures where the impact on family life is context-dependent and may be detrimental to parents' ability to balance work and family life (for more on this distinction, see Authors 2009).

Interviews were then conducted with HR managers $(\mathrm{n}=13)$ and with trade union representatives in two case study organizations per sector in each country. In addition, seven team leaders were interviewed in the case study organizations. Finally, interviews ( $n=18$ ) were conducted with fathers (ages ranging from 26 to 53) occupying various posts in the eight case study organisations.

The discussion that follows is based on a combination of the questionnaire data, case study research and interviews with fathers as described above. The low response rate, already noted, for the questionnaires means that the findings must be taken as indicative rather than nationally representative; however the triangulation and contextualization afforded by the case study design provide useful insights into the dynamic relationship between national context, organizational context and individual circumstance which was the focus of our project.

\section{FINDINGS AND DISCUSSION}

\section{The impact of national institutional frameworks on WLB measures}

Overall, legislation was cited as a key factor in the development of WLB measures in both countries. In the UK legislative change was seen as driving the introduction of both family-friendly/WLB measures and flexible working whereas in France legislative change (ie the reduction of the working week) was seen to have led to the introduction of more flexible working arrangements in insurance where negotiations over the reduction of working time had taken place. More than a quarter of insurance companies ( $N=21)$ responding in France mentioned the reduction in working time as a reason for developing greater flexibility in working time. Here, the reduction in working time had indeed encouraged greater variability in hours according to our survey, with a move to flexi-time or variable working hours and annualized hours. We also found widespread use of parttime work especially for women, which many respondents attributed to the impact of reduced working time: if full-time staff worked only 35 hours, it was presumably cheaper to employ staff on fewer hours and pay them an hourly part-time rate. In social work, the six departments which responded to this question stated that legislation had led to the introduction of WLB measures rather than to the variability of working hours, indicative 
of the differential impact of bargaining on working time in the public and the private sector.

The leadership of the organization (MD, Board of Directors and HR department) were, to a lesser extent, seen as instigators of change in the two countries. This seemed to be particularly the case in the UK although the relatively small number of French organizations responding to this question makes this difficult to confirm.

Finally, after the impetus from legislative change and HR management, a range of other factors contrasted with the French responses, which suggested a greater sensitivity of UK organizations to the market and its employees' needs. These were employee demand and commercial requirements such as service delivery which, our case study evidence suggested, had in some cases led to a reorganization of working time (eg. to lengthened opening hours in call centres). In UK social work, two case study organizations also reported responding to perceived employee demand, in a context of recruitment problems and competition to be seen as "employers of choice". This had led them to experiment with working time arrangements, with pilot schemes affecting particular teams or departments; this also contributed to the degree of variation in working time arrangements within the sector. A corresponding greater interest in monitoring employee satisfaction with their working conditions was found in the questionnaire data.

More generally, our questionnaire survey indicated that while statutory leaves (maternity, paternity, parental, family emergency leaves) were virtually universally available, provision of other flexibility measures was more variable and significant differences lay in the types of flexibility offered in the two countries. Term-time working, for example, was available almost exclusively in Britain whereas the annualization of working time (or use of a Compte Epargne Temps (CET) ${ }^{\mathrm{iv}}$ in France) was more widespread in France than in Britain. Annualized working hours had been negotiated in France within the context of working-time reduction (the 35-hour week). It is also important to mention the relative importance of home working in Britain, particularly in insurance as we discuss below. In France it is, by contrast, practically non-existent, as it is prohibited by the regulations governing public sector workers, and in the insurance industry it is resisted by employers (fearing loss of control) and trade unions (concerned about workers' protection); consequently, it tended to be sanctioned only in special cases for disabled or sick employees.

In general, the availability of WLB measures and flexible working arrangements was more rigidly codified in France than in Britain, where, instead, organizations appeared to have more discretion in the measures they could offer to their employees. In our questionnaire and case study research in UK social work, for example, it was possible to offer more flexible or reduced working hours on a "case by case" basis in order to meet workforce recruitment and retention objectives, which were of major importance at the time of the research. In France, by contrast, where public sector regulations dictate working conditions nationally, adapting working conditions to address recruitment objectives was prohibited. In both countries, however, larger insurers tended to be able to improve on the legislative minima, with the local labour market having a greater 
influence on provision as well. In British insurance for example, case study 2, a mediumsized specialist insurer, was located in a regionally tight labour market and it was understood by the Claims Management Departmental Head that..."modern managers have to understand that to retain staff who are competent that you do have to be flexible". In case study 4, a small specialist company, a flexi-time system had been introduced specifically to retain staff when their offices were moved to another town. In addition relocation and a mileage bonus were introduced.

The main WLB measure taken up by fathers was paternity leave in both countries, reflecting the recent legislative developments in this area. Our interviews with fathers, managers and trade union representatives confirmed that it was seen as normal to take up paternity leave in both the public and private sector in the two countries. However, in French insurance fathers highlighted the difficulty for managers of taking paternity leave.

On the other hand, formal records showed very low take-up of parental leave by fathers in both countries, even in France where the right has existed for a longer period ${ }^{\mathrm{v}} .12$ of the 17 French insurance companies responding to the question stated that no fathers took parental leave in their company. This apparent discrepancy between the questionnaire and interview data may reflect either widespread use of informal leave arrangements by father (e.g. through unpaid leave or informal cover arrangements with colleagues) or a lack of record-keeping at corporate level, with decisions being taken at line management level, or both. In the UK social work companies, for instance, the fathers we interviewed reported being able to negotiate longer periods of leave (often unpaid), for example when their partners suffered ill-health after childbirth or simply as a matter of personal choice, perhaps because career structures in social work were not linear, but rather career interruptions formed part of the normal pattern of work. These fathers did not distinguish between formal and informal leave and often could not remember the specific conditions in which they had taken leave.

Our findings cast doubt on the reported take-up of paternity leave in countries where statutory leave is paid at a low level and for short periods, as they suggest not only a higher level of demand for leave than the official figures reflect, but also potential for higher take-up for longer and better paid leave, as attitudinal surveys also indicate. Further research on men's use of paternity leave would be useful to elucidate these questions.

No other specific formal measures for fathers had been introduced in either country and in either sector to take into account men's domestic and parenting roles. However, our questionnaire survey in French insurance found that the reduction in working time to 35 hours had led to a reduction in annual working time for nearly half of the employees surveyed. Our interviews with fathers indicated that this new reduced working time had indeed given many fathers - certainly those without managerial responsibilities - the time to engage in childcare, at least in a supporting role (dropping/picking up children, getting home earlier to spend time with children). 
In French insurance the findings from our questionnaire and case studies, along with the interviews with trade unions representatives, found that the reduction in working time was explicitly linked to a greater, and usually negotiated, flexibility in working time (justified in terms of greater competitive pressures), by means of the annualization of working hours or its organization in monthly blocks of time. This could have mixed effects as our French mutual case study demonstrated. On the one hand the negotiations over working time had led to a 32 hour week but this had been implemented as four, eight-hour days with rotas to cover Wednesdays (when schools were often closed) in back office work and six hours 18 minutes over five days in call centres, creating (female) part-time jobs to cover the eleven-hour working day.

Finally, evidence from our case studies and interviews with fathers suggested that fathers were making less use of formal flexibility outside paternity leave as noted above and instead using a more universal flexibility in the form of flexi-time to adjust better to the demands of family life. This recourse to universal measures where fathers felt a sense of entitlement to WLB measures was complemented by informal adjustments in working time whose degree was strongly contingent on a range of sectoral factors such as the discretion of line managers (outlined below) and service delivery requirements. On the other hand, those measures linked to childcare were framed in gendered terms by employers and fathers correspondingly used them less

\section{Sectoral features of WLB}

Our questionnaire survey showed that Family-Friendly/WLB policies were, as we had expected, more widely available on paper in social work than in insurance. However, in practice their take-up was strongly influenced by the nature of the work in each sector. In social work formal work-life balance policies were eroded by the countervailing impact of other characteristics of the sector, in particular the time stresses resulting from heavy case loads generated by under-staffing, new government requirements for referrals to be dealt with in seven days, pressure to take post-qualifying awards without time off and additional administration generated by cuts in support staff for routine administration. This led to long working hours and home working during evenings and weekends. An experienced social worker in case study department 2 talked about the difficulties in using the Time Off in Lieu (TOIL) system, which is extensively used in social work..."it's abused, basically...if you were to go round the office you wouldn't find people clocking up all the TOIL that they do, because the nature of the job just sort of runs away with itself'. Cases require whatever time it takes.

Team working, which was most prevalent in social work, could enhance or damage an individual's ability to achieve work-life balance ${ }^{\text {vi }}$. In general, as other authors have noted, the team creates a feeling of solidarity which can cause a reduction in individual discretion over working time: team members are likely to see their working time affected by problems arising among other team members. Teams needed to ensure a minimum office presence or on-call availability so rostering posed problems of fairness, especially around times when individuals were likely to request home working or time off (notably Fridays in the UK and Wednesdays in France) or prefer not to work ie. evenings or 
weekends). However, our evidence from UK social work suggested that this loss of control had to be balanced against the advantage of sharing work when individual case loads became too heavy. Furthermore the autonomy of a team varies considerably between departments/areas of work within an organization and the specific organizational constraints of those departments. ${ }^{\text {vii }}$

In insurance availability of WLB measures was in practice dependent on the department and function (see below management versus non-management) and influenced by local factors such as the local labour market. In Case Study 2, for example, in some maledominated back-office departments relatively little formalized flexibility was scheduled (Finance and Accounts, IT, Corporate Governance) and employees worked long hours (around a core of 08/09 00-1700 and project-driven) with informal flexibility used for out-of-work commitments. On the other hand in other customer-facing departments (Calls Centres and Claims Management), where female staff were more numerous, and hours were more antisocial and included Saturday working, much more formalized flexible working was employed eg. shift working, part-time working, flexi-time in some cases.

While clear sectoral differences prevailed in the availability and take-up of work-life balance measures, certain similarities also existed across the sectors. WLB measures were available on paper to both men and women in both sectors. However, there was clear evidence of gendered flexibility in the way the measures were used by employees, particularly in insurance. In general, the more closely measures related to childcare, the more they were both targeted at, and taken up, by women. Family emergency leave, termtime working and school-hours working all represented "women's” forms of WLB and were almost exclusively used by women, as was to a lesser extent the ability to move to part-time work.

\section{Organizational features of WLB}

\section{(a) The management/non-management divide}

Non-managers had much greater access to formal WLB measures than managers, particularly in the UK. Because of their greater presence at higher levels of the organizational hierarchy, fathers are likely to be more affected by such a distinction than mothers. In UK insurance our interviews suggested that formal schemes for flexible working hours, flexi-time, job share and part-time work were practically exclusively the preserve of non-managers in practice, although only a small number of organizations responding to the questionnaire explicitly stated that managers were not permitted to adopt these working arrangements. In social work, we found the departments studied in the UK were very reluctant to allow reduced or flexible working hours by managers and, when it was achieved, as in the case of one manager, workload was not reduced accordingly. By contrast, job sharing was perceived by respondents to be more acceptable although availability varied from council to council.

On the other hand, interviews with trade union representatives, HR departments and managers in the case study organisations found that, on the one hand, managers often 
benefitted from discretion over their working hours (eg. they did not participate in a formal time management system) while, on the other, their working hours were typically above average for their organization, leading to stress ${ }^{\text {viii }}$. The case study research in the UK also found that they were significantly more likely to be able to work from home at least some of the time (for example, in three quarters of respondent companies in UK insurance). In insurance some posts, deemed to be at management level and dominated by male employees, were home-based (although not necessarily involving working at home) eg. claims inspector, sales consultancy, programmers, brokers, risk assessors. However, our interviews indicated that recourse to home working only partly responded to individuals' flexibility requirements, and in some cases, such as social work, reflected spillover from work to home, creating time pressures and stress (in line with other UK findings: see French and Daniels, 2005).

\section{(b) The importance of line managers}

Corroborating earlier research, our findings (both questionnaires and interviews) were that in most UK workplaces line managers are crucial in managing staff working hours and are the main conduit for requests for changes in working hours. In insurance their role had been recently bolstered by changes in the role of the HR departments in large companies where HR was becoming a shared service provider and acting in a consultancy role only. As the HR manager in British case study 1 reported: "we are trying to empower managers to effectively have their own little business. We want mangers to manage their people...it is a slow process, some are good, some aren't'.

In France, too, line managers played an important role but the human resources department remained the central point of reference (63\% of respondents in insurance and $80 \%$ in social work said they went through their HR department in France compared with $47 \%$ and $32 \%$ in the UK), confirming the primacy of legal obligations.

There were considerable sectoral differences in the degree of informal flexibility which line managers could allow, and these were particularly in evidence in the UK. In the insurance case studies some informal flexibility for short-term changes in hours was offered by line managers, depending on the nature of the work carried out (see above). By contrast, in UK social work the team manager appeared to allow and even encourage a greater level of informal flexibility, with both positive (ability to adapt rapidly to staff personal constraints and commitments) and negative (greater inequity between staff within and beyond the team) effects. Interviews with team managers found that being flexible was considered to be key to preventing staff burnout and depended also on staff being "mature" and communicating their hours to each other responsibly.

The case study research in the UK suggested that the line manager's attitude towards working time strongly influenced employees' perception of their own entitlement to WLB measures, creating in effect a local working time culture. The Amicus officer in insurance case study 1 stated in this respect that “There is a long hours' culture in [company 1]. It does vary. In some cases there is more pressure to conform than in other areas and a lot of that is to do with who is there as the senior manager and how they lead by example". In social work, if managers themselves talked about their children and felt 
able to clock off, they allowed others to do so, whereas if they "worked all hours", other employees felt obliged to do the same; managers were routinely classed as "good" or "bad" on this criterion. UK social workers interviewed in the case study research freely described managers they had previously worked with who had been less than sympathetic to work-life concerns, suggesting that access to WLB measures in social work in particular was down to luck and a source of inequality.

\section{CONCLUSION}

This paper explored the impact of national institutional frameworks for work-life balance - within the broader context of national fatherhood regimes - on work organizations and on fathers' take-up of such measures, and the ways in which organizational (and sectoral) constraints shape WLB policy provision and delivery, particularly as they relate to fathers.

In response to our first question, we explored the importance of fatherhood regimes for organizational WLB policy and practice. Whilst we acknowledge the difficulties of generalizing from our small sample, our sectoral focus has allowed us to explore more fully findings from other national and comparative surveys about the relationship between organizations, sectors and national policy. We found evidence of significant differences in the way temporal flexibility is organized and experienced in the two countries, which we argue warrant further research. We have noted that a relationship exists between these temporal arrangements and the broader "gender order". We have identified gendered notions of parenting within evolving "fatherhood regimes" which, whilst redefining fathers' roles within the household, still tend to maintain a gendered division between the public and private sphere. In the UK, despite a discourse of gender neutrality, a tension between family law and employment law has been noted in this respect, whilst in France gendered assumptions about the provision of childcare mean that work-life balance policies are framed, sometimes explicitly, in terms of mothers' need to reconcile home and family life.

Whilst France has a highly codified approach to labour market regulation, our study has found working-time reduction to have ushered in some degree of "chosen" flexibility, particularly for non-managers: that is, more leisure time which can be used to suit family and other commitments. On the other hand it appears to have generated more anti-social working for some parents. The UK’s liberal policy rhetoric about workplace flexibility, however, conceals significant organizational obstacles to temporal flexibility, relating to the individual discretion of line managers and service delivery requirements. Reliance on informal arrangements and individual line managers created an atmosphere in which time for childcare had to be negotiated rather than being seen as an entitlement, and was easily constrained by business delivery needs or the difficulties of balancing needs across a team of workers. In both countries, organizations' inability to see managerial jobs other than in terms of limitless time sacrifice can affect not only the WLB of managerial staff, but also of the employees they manage.

Our research also supports earlier work indicating an important sectoral influence on the development of WLB policy and practice. Notably, as predicted, family-friendly/WLB 
measures seem to be more available, on paper at least, in social work. Our survey of insurance and social work in Britain and France finds that key variables in WLB policy and practice are the nature of the business (and its regulation), related time demands and the division of labour (notably job function). These findings corroborate a French survey (Lefevre et al, 2007) which notes the concentration of family-friendly measures in certain sectors (especially in the public sector) and among particular occupational groups.

We have emphasized in this paper that fathers' up-take of WLB policies is the outcome of a complex dynamic between the fatherhood regime, organizational characteristics and the individual. We have identified the organization as playing an important mediating role between the state and the individual/household. If it were true, as it has been suggested for Sweden, that organizational development of WLB measures is weak because of the strong role of the state and resultant cultural expectations (eg. Haas et al, 2000), we would have expected to see strong organizational development in the UK and rather weaker development in France. This hypothesis is partly borne out because we found greater space for experimentation around flexibility measures in the UK than in France. However, we found that the organization was an important site of negotiation of flexibility and time trade-offs in France because of the impetus of legislative change and workplace bargaining on working time.

In both countries, organizational initiatives and pressures are identified as an important motivating factor in the development and availability of WLB measures. However, the role of the state in developing the agenda of WLB and, in particular, a family-friendly agenda is crucial. The differences noted between the two countries indicate that the way policies are framed at national level influences organizational behaviour: first, statutory provision is found to be a strong determinant of change in provision; second, it is the vehicle for cultural norms such as the model of the "working mother" in France or the part-time female carer in the UK, which has a reciprocally influential relationship with labour market behaviour. Such norms were articulated in our questionnaire findings and in our interviews with managers.

Our findings suggest that the availability and take-up of WLB measures are strongly gendered within organizational settings, as a result of the way policies are framed and implemented by line managers, and as a result of societal norms and expectations influencing individual behaviour. This is despite evidence cross-nationally that fathers would like more flexibility in the way they balance work with family commitments.

On the other hand, there is evidence that where WLB measures are specifically targeted at fathers (paternity leave) or expressed as universally available flexibility measures (flexi-time/reduced working time or compressed hours for an entire team), rather than associated with parental responsibilities, fathers feel able to use them to spend more time with their families. These findings have implications for the way policies are formulated at national and organizational level.

\section{References}

Authors (2006) 
Authors (2008)

Authors (2009)

Bittman, M., Thompson, S. and Hoffmann, S. (2004) “Men’s take-up of family-friendly employment provision”, Policy Research Paper, Canberra, Department of Family and Community Services.

Björnberg, U. (2000), "Equality and backlash: Family, gender, and social policy in Sweden”, Haas, L., Hwang, P. and Russell, G. (Eds), Organisational Change and Gender Equity: International Perspectives on Fathers and Mothers at the Workplace, Sage, Thousand Oaks, pp. 57-75.

Bond, S., Hyman, J., Summers, J. and Wise, S. (2002), Family-Friendly Working? Putting Policy into Practice, Joseph Rowntree Foundation, York.

Brandth, B. and Kvande, E. (2001), "Flexible work and flexible fathers” Work, Employment and Society, Vol. 15, No. 1, pp. 251-267.

Brannen, J. and Moss, P. (1998), "The polarization and intensification of parental employment in Britain : consequences for children, families and the community”, Community, Work and Family, Vol. 1, No. 3, pp. 229-247.

Cousins, C.R. and Tang, N. (2004) "Working time and work and family conflict in the Netherlands, Sweden and UK”, Work, Employment and Society, Vol. 18, No. 3, pp. 531549.

Crompton, R., Brockman, M. and Lyonette, C. (2005), “Attitudes, women’s employment and the domestic division of labour: a cross-national analysis in two waves", Work, Employment and Society, Vol. 19, No. 2, pp. 213-234.

das Dores Guerreiro, M. and Pereira, I. (2007), "Women’s occupational patterns and work-family arrangements: do national and organizational policies matter?”, Crompton, R., Lewis, S. and Lyonette, C. (Eds), Women, men, work and family in Europe, Palgrave, London and New York, pp. 171-189.

Demetriades, S., Meixner, M. \& Barry, A. (2006), Reconciliation of Work and Family Life and Collective Bargaining in the European Union. An analysis of EIRO articles, Dublin: European Foundation for the Improvement of Living and Working Conditions.

Dermott, E. (2008), Intimate Fatherhood. A Sociological Analysis, Routledge, London.

Dex, S. and Smith, C. (2002), The Nature and Pattern of Family-Friendly Employment in Britain, Policy Press and Joseph Rowntree Foundation, Bristol.

Fagnani, J. and Letablier, M.-T. (2007), "The French 35-hour working law and the worklife balance of parents : friend or foe?”, Perrons, D., Fagan, C., McDowell, L., Ray, K. 
and Ward, K. (2007) (Eds), Gender Divisions and Working time in the New Economy. Changing Patterns of Work, Care and Public Policy in Europe and North America, Edward Elgar, Cheltenham, pp. 79-90.

Fagnani, J. and Letablier, M.-T. (2004), "Work and family life balance: the impact of the 35-hour laws in France”, Work, Employment and Society, Vol. 18, No. 3, pp. 551-572.

Ferri, E. et Smith, K. (1996), Parenting in the 1990s, Family and Parenthood Series. Family Policy Studies Centre, London.

Fleetwood, S. (2007), “Why WLB now?”, International Journal of Human Resource Management, Vol. 18, No. 3, pp. 387-400.

French, S. and Daniels, G. (2005), “WLB: evidence from across the UK”, European Industrial Relations Review, Vol. 380, pp. 27-29.

Gambles, R., Lewis, S. and Rapoport, R. (2006), Work-personal life harmonisatio,. Wiley, Chichester.

Gambles, R., Lewis, S. and Rapoport, R. (2007), “Evolutions and approaches to equitable divisions of paid work and care in three European countries: a multi-level challenge”, Crompton, R., Lewis, S. and Lyonette, C (Eds) Women, men, work and family in Europe, Polity, Cambridge, pp. 17-34.

Gornick, J. C. and Meyers, M. K. (2004), "Welfare regimes in relation to paid work and care”, Zollinger Giele, J. and Holst, E. (Eds.) Changing Life Patterns in Western Industrial Societies, Elsevier Science Press, Amsterdam, pp.45-67.

Haas, L.L., Hwang, P. and Russell, G. (Eds) (2000), Organisational Change and Gender Equity: International Perspectives on Fathers and Mothers at the Workplace, Sage: Thousand Oaks.

Haas, L.L. and Hwang, P. (2007), “Gender and organizational Culture: Correlates of companies’ responsiveness to fathers in Sweden”, Gender and Society, Vol. 21, No. 1, pp. 52-79.

Halrynjo, S. (2009), “Men’s work-life conflict: Career, care and self-realization”, Gender, Work and Organization, Vol. 16, No. 1, pp.98-123.

Hatten, W., Vintner, L. and Williams, R. (2002), Dads on Dads: Needs and Expectations at Home and at Work, Equal Opportunities Commission, London.

Hobson, B. and Martin, D. (2002), “Introduction”, Hobson, B. (Ed.), Making men into fathers. Men, masculinities and the social politics of fatherhood, Cambridge University Press, Cambridge, pp 1-21. 
Holter, O. G. (2007), “Men’s work and family responsibilities in Europe”, Men and Masculinities, Vol. 9, pp. 425-457.

Künzler, J. (2002), "Paths towards a modernization of gender relations, policies and family building”, Kaufmann, F.-X., Kuyser, A., Schulze, H-J. and Strohmeier, K.-P. (Eds), Family Life and Family Policies in Europe, Vol. II, Problems and Issues in Comparative Perspective. Oxford University Press, Oxford, pp. 252-298.

Kvande, E. (2009), "Work- life balance for fathers in globalized knowledge work: some lessons from Norway”, Gender, Work and Organization, Vol. 16, No. 1.

Lamb, M.E., Pleck, J.H., Charnov, E.L. and Levine, J.A. (1997), “A biosocial perspective on paternal behaviour and involvement”, Lancaster, J. B., Altman, J., Rossi, A. and Sherrod, L. R. (eds) Parenting across the lifespan: Biosocial perspectives, Academic Press, New York, pp. 11-43.

Langvasbräten, T. and Teigen, M. (2006), "Fostering caring masculinities (FOCUS project)”, Research Paper, October, Institute for Social Research, Norway.

Le Feuvre, N. and Lemarchant, C. (2007), "Employment, the Family and 'WLB' in France”, Crompton, R., Lewis, S. and Lyonette, C (Eds), Women, men, work and family in Europe, Polity, Cambridge, pp. 210-229.

Lewis, S. and Smithson, J. (2001), "Sense of entitlement to support for the reconciliation of employment and family life”, Human Relations, Vol. 54, No. 11, pp. 1455-1481.

McDonald, P., Brown, K. and Bradley, L. (2005), "Explanations for the provisionutilisation gap in work-life policy”, Women in Management Review, Vol. 20, No. 1, pp. 37-55.

Méda, D. and Orain, R. (2002), « Transformations du travail et du hors-travail: la formation du jugement des salariés sur la RTT », Travail et Emploi, No. 90, avril.

OECD (2004), Babies and Bosses - Reconciling Work and Family Life, Vol 4: Canada, Finland, Sweden, United Kingdom, OECD, Paris.

Pailhé, A. and Solaz, A. (2006), « Vie professionnelle et naissance: la charge de la conciliation repose essentiellement sur les femmes », Population et Sociétés, No. 426 (4pp).

Perrons, D., Fagan, C., McDowell, L., Ray, K. and Ward, K. (2007), Gender Divisions and Working time in the New Economy. Changing Patterns of Work, Care and Public Policy in Europe and North America, Edward Elgar, Cheltenham.

Silvera, R., Buseyne, N. and Donlevy-Gomes, V. (2004), Articuler vie professionnelle et vie personnelle. Les expériences des projets Equal français 2001-2004, RACINE, Paris. 
Smeaton, D. and Marsh, A. (2006), Maternity and paternity rights and benefits: Survey of parents 2005, Department of Work and Pensions, Employment Relations Research Series, No. 50, London.

Singley, S. and Hynes, K. (2005), “Transitions to parenthood. Work-family policies, gender and the couple context, Gender and Society, Vol. 19, No. 3, pp. 376-397.

Smithson, J. and Stokoe, E.H. (2005), "Discourses of WLB:Negotiating "genderblind” terms in organizations”, Gender, Work and Organization, Vol. 12, No. 2, pp. 147-168.

Sullivan, O. (2004), "Changing gender practices within the household: A theoretical perspective”, Gender and Society, Vol. 18, No. 2, pp. 207-222.

Wall, K. (2007), "Main patterns in attitudes to the articulation between work and family life: A cross-national analysis”, Crompton, R., Lewis, S. and Lyonette, C (Eds) ,Women, men, work and family in Europe, Polity, Cambridge, pp. 86-115.

Warren, T. (2003), “Class and gender-based working time? Time poverty and the division of domestic labour”, Sociology, Vol. 37, No. 4, pp. 733-752.

White, M., Hill, S., McGovern, P., Mills, C. and Smeaton, D. (2003), “'Highperformance' management practices, working hours and work-life balance”, British Journal of Industrial Relations, Vol. 41, No. 2, pp. 175.

Wise, S. and Bond, S. (2003), “Work-life policy”, Women in Management Review, Vol. 18, pp. 20-31. 


\section{End Notes}

i In this article we use the term "work-life balance", in line with standard European Union definitions (Demetriades, Meixner \& Barry, 2006), to include a wide variety of measures including special leave and career breaks; part-time working and job-sharing; flexi-time; compressed working week; annualised hours schemes; term-time working; home-working; and childcare support (see authors, 2009a).

ii Law No. 2007-1223 of 21 August 2007 (known as the TEPA law) followed by the Law of 20 August relating to the renewal of social democracy and reform of working time, and the related decree of application (2008-1132 of 4 November 2008) have sought to encourage overtime working and greater flexibility in the organization of working time by employees and businesses. iii The CNAF project was entitled "Les pères a la recherche d'un nouvel equilibre entre responsabilites familiales et professionnelle - une comparaison franco-britannique”; British Academy Small Grant no.SG-36628 “Men and Family-friendly Employment: An Anglo-French Comparison.

iv The CET is a method of accumulating time off work, payments or a combination of the two. It can be used to "bank" time for a later date eg. the "heures RTT" - time off accorded to managers to whom the general reduction in working time to 35 hours did not apply.

${ }^{v}$ Parental leave was introduced in 1984 in France (Law of 4 January) and in 1999 in the UK (Employment Relations Act, 1999).

${ }^{v i}$ It was, however, used in specific areas of work in insurance (eg. call centres, some claims offices; some project management activities)

${ }^{\text {vii }}$ For example, teams working closely with other services or reporting directly to other services have less autonomy than others. Teams' working arrangements are also heavily dependent on rosters whereby a certain minimum number of present or on-call staff need to be guaranteed at certain times; small teams therefore have less autonomy than larger teams.

viii The reduction of working time in France had not reduced work pressure for managers: their reduction of working time package typically comprised an increase in their holiday allocation but in practice many managers were using these days' leave to meet workload requirements. 